den großen Moskauer Schauprozessen wurden nicht nur ehemalige Kritiker Stalins und potenzielle Konkurrenten ausgeschaltet, sondern größtenteils physisch vernichtet. Im Grunde genommen wurden unter anderem die ehemaligen Gefährten Lenins wie »Klassenfeinde« behandelt und sogar dazu gezwungen, sich durch ihre »erpressten Geständnisse« im Kontext der stalinistischen Säuberungen ihren »Henkern« sozusagen selbst auszuliefern.

\title{
2.5 Der Stalinismus nach dem Ende des Zweiten Weltkrieges
}

Die Sowjetunion hatte einen entscheidenden Anteil daran, dass die alliierten Mächte aus dem Krieg mit dem Nationalsozialismus als Sieger hervorgingen. Der Preis, den sie im existenziellen Kampf mit »Hitler-Deutschland « zahlen musste, war allerdings hoch: Der Kampf der Roten Armee mit der Wehrmacht kostete nicht nur Millionen von Menschenleben, hinzu kam, dass die soziale Lage der sowjetischen Bevölkerung katastrophal war, unzählige Städte zerstört waren und das ganze Land wirtschaftlich ausgeblutet war. Gleichwohl war der militärische Kampf am Ende für Stalin nicht umsonst, denn es war ihm gelungen, das sowjetische Territorium auszudehnen; es ging sogar in erheblichem Maße über die Zusicherungen aus dem 1939 mit Hitler abgeschlossenen Vertrag hinaus. ${ }^{448}$ Der sowjetische Einflussbereich erstreckte sich unter anderem über sämtliche Länder Ostmitteleuropas, d.h. Polen, die Tschechoslowakei, Rumänien, Bulgarien, Ungarn, Jugoslawien und Albanien. Auch im besetzten Deutschland wollte Moskau ein entscheidendes Wort mitsprechen und verlangte in den Jahren des sich immer mehr zuspitzenden Kalten Krieges seinen Anteil. ${ }^{449} \mathrm{Zu}$ den politischen Folgen des Kalten Krieges zählte, dass Stalin den außenpolitischen Kurs in den Satellitenstaaten verschärfte. Unter anderem in Gestalt der im September 1947 gegründeten Kominform - der Nachfolgeorganisation der während des Zweiten Weltkrieges zu Grabe getragenen Komintern - sah Moskau ein geeignetes Instrument, im Zuge der Realisierung des (alten) zentralen Zieles, der kommunistischen Weltrevolution, über den Einfluss in den nationalen kommunistischen Parteien nicht zuletzt den Satellitenstaaten das kommunistische System sowjetischer Couleur aufzuzwingen. ${ }^{450}$

Nach den Gewaltexzessen des stalinistischen Herrschaftssystems in den 1930erJahren und den schrecklichen Erfahrungen des Zweiten Weltkrieges wurde aufkommenden Hoffnungen in der sowjetischen Bevölkerung auf eine allgemeine Verbesserung des Lebens und ein Ende des politischen Terrors sehr bald ein Ende bereitet. Nachdem bereits im Krieg gegen das nationalsozialistische Deutschland politisch »unzuverlässige Elemente« und "nationale Minderheiten« - wie zum Beispiel die Wolgadeutschen - zu Hunderttausenden deportiert wurden und unter anderem in den sowjetischen Lagern Zwangsarbeit vollrichten mussten, verschärfte sich die Situation nach einer kurzen liberalen Phase nach Kriegsende sehr schnell. In der Folgezeit wurde das System der Zwangsarbeit ausgedehnt. Nicht zuletzt vor dem Hintergrund

448 Vgl. zum Hitler-Stalin-Pakt A. Rossi, Zwei Jahre deutsch-sowjetisches Bündnis. Eine historische Rekonstruktion, in: Der Monat 1 (1949), H. 11, S. 74-98 (Teil I) und H. 12, S. 40-55 (Teil II). Auf die beiden Beiträge gehe ich in Kap. IV.3 ein.

449 Vgl. hierzu im Einzelnen die entsprechenden Ausführungen in Kap. I.2.

$450 \mathrm{Zu}$ den Unterschieden zwischen Komintern und Kominform vgl. insgesamt Franz Borkenau, Die Neue Komintern, in: Der Monat 1 (1949), H. 4, S. 50-60. 
der Einführung des neuen Fünfahresplanes für die Jahre 1946 bis 1950 nahm die Zahl der Häftlinge in den Lagern des Gulag im Vergleich zu den 1930er-Jahren radikal zu. »Neue Gruppen« gerieten in die Fänge der sowjetischen Führung unter Stalin und bildeten in diesem Zusammenhang das mehrere Millionen umfassende Reservoir von Zwangsarbeitern. So wurden beispielsweise im Jahre 1946 drei Millionen Kriegsgefangene, darunter schätzungsweise zwei Millionen Deutsche, bei der Durchführung von »kolossalen Projekten« beschäftigt, so Dallin und Nikolajewski in ihrer Studie Arbeiter oder Ausgebeutete? Das System der Arbeitslager in Sowjet-Russland unter Berufung auf »sowjetische Quellen« ${ }^{451}$ Hinzu kamen mehrere Millionen russischer Kriegsgefangener, Männer und Frauen, die im Verlauf des Zweiten Weltkrieges in deutsche Gefangenschaft gerieten - und zum Teil in Deutschland zur Zwangsarbeit eingesetzt wurden - sowie sogenannte Kollaborateure wie zum Beispiel Angehörige der »Wlassow-Armee ${ }^{452}$ Sie wurden als »Vaterlandsverräter« und »unzuverlässige Elemente « angesehen und bildeten unter anderem eine weitere zahlenmäßig umfangreiche "neue Gruppe«, die in den Lagern des sowjetischen Staates Zwangsarbeit vollrichten mussten. ${ }^{453}$

Auf die politische Bedeutung und die Funktion des sowjetischen Systems der Arbeits- und Straflager kam im Monat unter anderem Lüthy im Kontext seiner Ausführungen zum »Rousset-Prozess« im Jahre $1950 \mathrm{zu}$ sprechen. Angesichts der Tatsache, dass erstens die russischen Archive noch verschlossen waren und mithin die internationale Forschung sich vor allem auf die zahlreichen Erinnerungen und Memoiren beispielsweise der Renegaten stützte (Buber-Neumann, Kriwitzki, Krawtschenko, Lipper, Weißberg-Cybulski u.a.), sodass nicht zuletzt die Zahl der Häftlinge auf »Schätzungen« beruhten, zweitens die internationale Öffentlichkeit nur teilweise Kenntnis über die Lager des Gulag besaß und drittens vor allem die französische (kommunistische) Linke und französische (Links-)Intellektuelle die Existenz der sowjetischen Lager leugneten, den politischen Charakter herunterspielten bzw. über das Thema den Mantel des Schweigens hüllten, ${ }^{454}$ schrieb Lüthy in seinem Beitrag David Roussets »Je propose ...«. Die Untersuchung der Verschleppten durch Verschleppte:

Diesen Sommer hat die britische Regierung der Weltöffentlichkeit und den Instanzen der Vereinten Nationen erstmals den Wortlaut der russischen Zwangsarbeitsgesetzgebung vorgelegt, und die Vertreter der Sowjetunion haben über Einzelheiten und Interpretationen diskutiert, aber nicht die Echtheit dieses juristischen Monuments bestritten, das die willkürliche Verschickung von Menschen als rechtloses, nach den Prinzipien altorientalischer Sklavenwirtschaft amortisiertes (d. h. im wörtlichen Sinn: zu Tode geschundenes) Arbeitsvieh des »sozialistischen Aufbaus« in Sümpfe, Wälder und Steppen, ohne Urteil und ohne Begründung, durch einfache administrative Verfügung, bürokratisch in dürre Paragraphen faßt. Und diese Administration ist niemand anders

451 Dallin/Nicolaevsky, Arbeiter oder Ausgebeutete, S. 137.

452 Vgl. zur »Wlassow-Armee« im einzelnen George Fischer, Der Fall Wlassow, in: Der Monat 3 (1951), H. 33, S. 263-279, sowie H. 34 (S. 393-408) und H. 35 (S. 519-525).

453 Vgl. hierzu im Einzelnen Dallin/Nicolaevsky, Arbeiter oder Ausgebeutete, S. 138-153.

454 Hier lag - wie gezeigt - auch der eigentliche >Sprengstoff $<$ des Rousset-Prozesses im Allgemeinen und des Krawtschenko-Prozesses im Besonderen, vgl. hierzu mit entsprechenden Angaben vor allem zu den veröffentlichten Beiträgen im Monat das Kap. III. 
als die politische Polizei selbst, ein immenser Staatstrust, der durch diese fast kostenlos »eingesetzten «Arbeitermassen sich und seine übrigen Tätigkeiten selbst finanziert und seine Sklavenherden aus eigener Machtvollkommenheit durch immer neue Verhaftungen stets neu rekrutiert.

Langsam beginnt sich die Landkarte dieses infernalischen Reiches abzuzeichnen, dessen Einzellager, Regionen und Provinzen von der Beringstraße durch Sibirien und Zentralasien bis vor die Tore Moskaus und Leningrads zerstreut liegen, das von einer nur schätzbaren, auf jeden Fall zehn Millionen übersteigenden Zahl von Gefangenen bevölkert ist, die in schnellem Rhythmus absterben und in noch schnellerem Rhythmus neue angeliefert werden, und das schon seine ersten Enklaven bis zur Donau und zur Elbe vorgetrieben hat. Und es ist klargeworden, daß diese Zwangsarbeitslager nicht, wie die deutschen Konzentrationslager, ein abscheulicher Auswuchs des Terrors und des totalen Krieges sind, sondern daß sie einen permanenten wirtschaftlichen Zweck erfüllen und ein wesentlicher, nicht wegzudenkender Teil des russischen Wirtschaftsund Sozialsystems sind [...]. ${ }^{455}$

Obwohl die Konzentrationslager unter Stalin nach dem Ende des Zweiten Weltkrieges wie in den Jahren zuvor auch eine politische (Terror-)Bedeutung besaßen - zumal alsbald in der Partei eine erneute »Säuberungsaktion« in Gang kam; dazu gleich mehr - , wies Lüthy zu Recht darauf hin, dass zum einen die sowjetischen Lager in den Jahren nach dem Krieg insbesondere eine wirtschaftliche Funktion hatten und sich aus diesem Grund die Häftlingszahlen im Vergleich zu der Vorkriegszeit extrem erhöhten und zum anderen, dass sich das sowjetische Lagersystem keineswegs ausschließlich auf das eigene Territorium beschränkte. So beleuchtete, genauer gesagt untersuchte Günther Birkenfeld im Monat bereits im Jahre 1950 in seinem Beitrag Der NKWD-Staat, wie sich die stalinistischen Konzentrationslager auf den sowjetisch besetzten Teil Deutschlands, d.h. auf die sowjetische Besatzungszone, ausbreitete und insistierte hierbei in erster Linie auf den politischen Charakter und den politischen Terror. In den einleitenden Worten der Zeitschriftenredaktion zu dem Beitrag von Birkenfeld hieß es zu Beginn: »Mündliche und schriftliche Berichte ehemaliger Internierter aus den Konzentrationslagern im sowjetisch besetzten deutschen Gebiet lieferten das Material für diese Untersuchung, mit der versucht wird, Wesen und Absicht des NKWDSystems der >politischen Internierung a auf deutsche[m] Boden zu erkennen. « ${ }^{456}$

Der Beitrag stellte mithin eine genuine Untersuchung dar, die empirisch ausgerichtet war - die Grundlage bildete die »Fülle der Protokolle in Form eidesstattlicher Zeugenaussagen, die von den Entlassenen bei der >Kampfgruppe gegen Unmenschlichkeit niedergelegt wurden ${ }^{457}$ - und sich zum damaligen Zeitpunkt auf keine genuine Forschungsliteratur stützen konnte. Insofern betrat Birkenfeld politisch und wissenschaftlich durchaus »Neuland«. Zu Beginn seiner 16 Seiten umfassenden Studie schrieb der Verfasser:

455 Herbert Lüthy, Brief aus Paris: »]e propose ...«. Die Untersuchung der Verschleppten durch Verschleppte, in: Der Monat 2 (1950), H. 16, S. 353-356, hier S. 353.

456 Günther Birkenfeld, Der NKWD-Staat, in: Der Monat 2 (1950), H. 18, S. 628-643, hier S. 628.

457 Siehe hierzu im Einzelnen die weiteren Erläuterungen der Zeitschriftenredaktion, in: Ebd., S. 628. 
Das NKWD-System gliedert sich, vom Häftling gesehen in drei Phasen, die ihre spezifische Methodik besitzen: Verhaftung; Untersuchung nebst Vernehmungen; das Lager (unter Umständen auch Cefängnis oder Zuchthaus). Von diesen drei Phasen ist die dritte, das Konzentrationslager, für unsere Fragestellung die wichtigste und aufschlußreichste. Aber eine kurze Betrachtung der Methodik der ersten beiden Phasen darf, zur Herausarbeitung des vollständigen Systems, nicht fehlen.

Die Verhaftungen begannen sogleich nach der Besetzung der deutschen Cebiete durch die Sowjetstreitmacht. Sie wurden zunächst von Angehörigen der Sowjetarmee oder der NKWD durchgeführt, in jedem Falle unter der Leitung der NKWD (früher GPU, neuerdings MWD), deren Zentrale das Volkskommissariat für Innere Angelegenheiten in Moskau ist. Seit dem Frühjahr 1946 wurde mehr und mehr die inzwischen organisierte ostzonale deutsche Polizei (Volkspolizei), die ihre Richtlinien und Vollzugsanweisungen von der NKWD erhält, mit der Durchführung der Verhaftungen beauftragt. ${ }^{458}$

Birkenfeld konstatiert, dass die Zuständigkeit für die Verhaftungen in der sowjetischen Besatzungszone in Moskau lag und vom NKWD (bzw. deren Nachfolgeorganisation MWD) sowie seit dem Frühjahr 1946 insbesondere von der »ostzonale[n] deutsche[n] Polizei« durchgeführt wurden, kam der Verfasser im nächsten Abschnitt darauf zu sprechen, welche Personengruppen im Jahre 1945 vom NKWD-Terror betroffen waren. »Die Verhafteten«, so Birkenfeld,

lassen sich in zwei Gruppen einteilen. Zur ersten gehörten die Naziverbrecher, Kriegsverbrecher, Verbrecher an Kriegsgefangenen und Fremdarbeitern und alle diejenigen, die fälschlich in einen entsprechenden Verdacht gerieten. Sie machten 1945 etwa 50 Prozent der Gesamtzahl der politischen Internierten aus. Die zweite Gruppe, die anderen 50 Prozent, bestand aus Angehörigen der Intelligenz und der »Bourgeoisie« (sowjetischer Sammelbegriff: Kapitalisten); aus Mitgliedern der bürgerlichen Parteien und der Sozialdemokratie, die den Einheitskurs der Kommunistischen Partei (später SED) nicht in allen Punkten mitmachen konnten oder böswillig der »Sabotage« verdächtigt wurden; ebenso Studentenvertreter, die der CDU, LDP oder SPD angehörten oder nahestanden; [...]. Andere Gruppen von Unschuldigen, die das Pech hatten, in die Fänge der NKWD zu geraten, waren: Deutsche, die mit einer westlichen Besatzungsmacht in Beziehung standen oder dessen verdächtigt wurden (mitunter genügte die Kenntnis der englischen Sprache), illegale Grenzgänger; von Nachbarn Denunzierte, Kellner und andere Personen, die mit verdächtigen Sowjetbürgern in Berührung kamen; ja, auch Passanten, die einem der berüchtigten »Todesmärsche« der bereits Internierten (von Lager zu Lager) begegneten. Denn brachen dabei Häftlinge auf der Landstraße tot zusammen (auf jedem dieser Märsche mindestens vierzig), so wurde der nächste Bauer vom Pfluge, der Chauffeur oder Fuhrmann von seinem Fahrzeug in die Kolonne der Dahinwankenden hinein verhaftet. Die Sollzahl mußte bei der Ablieferung der Internierten im neuen Lager stimmen.

Birkenfeld zeigte auf der Grundlage des empirischen Materials für seine Untersuchung sehr detailliert, anhand welcher Kategorien unmittelbar nach Kriegsende die zwei Personengruppen vom NKWD verhaftet und in die stalinistischen Lager in der 
sowjetischen Besatzungszone geliefert wurden. Hierbei handelte es sich keineswegs nur um »objektive Gegner«, also ehemalige Nationalsozialisten, die verdächtig wurden, unterschiedliche (Kriegs-)Verbrechen begangen $\mathrm{zu}$ haben und analog $\mathrm{zu}$ den westlichen Besatzungszonen als "politisch Internierte« sozusagen aus »guten Gründen« verhaftet wurden. Der totalitäre Charakter des NKWD-Systems kam dadurch zum Ausdruck, dass nicht nur die aus der Sicht Stalins "natürlichen« weltanschaulichen Feinde wie zum Beispiel die »Bourgeoisie«, Mitglieder der bürgerlichen Parteien oder Sozialdemokraten (die sich dem von Moskau aus befohlenen und gesteuerten »Einheitskurs« der kommunistischen Partei bzw. der späteren SED, so Birkenfeld, widersetzt hatten), sondern vor dem Hintergrund, dass die »Sollzahlen« für die Lager erreicht werden mussten, bereits 1945 die gesamte Bevölkerung Ostdeutschlands verdächtig war und potenziell Opfer von Verhaftungen werden konnte, ohne dass hierfür eine Rechtsgrundlage vorhanden war. Die Willkür des NKWD-Terrors, die in den Ausführungen Birkenfelds hervorgehoben wurde, war bereits ein Jahr später nach Auffassung des Autors im Grunde genommen offensichtlich - obwohl es sich in den Augen der sowjetischen Führung um politische Gefangene, genauer um die "politischen Internierten« handelte. Denn:

Seit dem Jahre 1946 wurde[n] ehemalige Nationalsozialisten nur noch in verschwindender Zahl verhaftet, hingegen sehr viele alte Sozialdemokraten und sogenannte "Saboteure der volksdemokratischen Einheit und des Aufbaus«. (Verläßliche Statistiken fehlen hier noch.) Unter diese Formel fiel fast alles, was irgendwie lästig oder mißliebig geworden war, besonders aber Deutsche in der Sowjetzone, die zuviel wußten, die einen gar zu intimen Einblick in die Praktiken der Sowjets und der NKWD gewonnen hatten. Sehr aufschlußreich ist, daß die ersten beiden Entlassungswellen in den Jahren 1948 und 1949 nahezu ausschließlich den sogenannten kleinen Pg's die Freiheit verschafften, nachdem 1948 die Nationaldemokratische Partei als Hilfsgruppe der SED gegründet worden war. Diejenigen politischen Internierten aber, die sich in irgendeinem Sinne als Gegner des sowjet-deutschen Systems zu erkennen gegeben hatten oder fälschlich in diesen Verdacht gerieten, besonders die Altsozialdemokraten, wurden auch nach der Auflösung der Konzentrationslager im sowjetisch besetzten Gebiet im Januar 1950 noch nicht entlassen. ${ }^{459}$

Nachdem von Birkenfeld in seiner Untersuchung detailliert die verschiedenen Opfergruppen aufgezählt wurden, die in den ersten Jahren von der sowjetischen Besatzungsund Verhaftungspolitik im von ihr besetzten Teil Deutschlands betroffen waren, die in einem totalitären politischen Kontext stattfand, wo im Grunde genommen jeder einzelne Bürger gefährdet war, in die >Fänge des NKWD bzw. der sogenannten ostzonalen deutschen Polizei zu geraten, beschrieb der Autor - nach näheren Ausführungen zur konkreten Verhör- und Folterpraxis des NKWD ${ }^{460}$ - insbesondere das System der Konzentrationslager. In diesem Zusammenhang schrieb er u. a. aus einer totalitarismustheoretischen Perspektive, indem er die stalinistischen Konzentrationslager in der Sowjetunion und in der sowjetischen Besatzungszone mit den nationalsozialistischen Konzentrationslagern verglich: 
Die seit dem Jahre 1945 auf sowjetisch besetztem deutschen Boden gelegenen alten KZ's der SS sowie die neu eingerichteten KZ's dürfen nicht ohne weiteres mit den KZ's der Nazis identifiziert werden. Sie waren, wie im folgenden nachzuweisen sein wird, in mancher Hinsicht anders und neuartig - das erste große Experiment der NKWD auf fremdem Territorium. Die Zwangslager in der Sowjetunion sind Arbeitslager. Die politischen Internierten und ihr Leidensgenossen hausen in großen Holzbaracken in einsamer Landschaft und werden zu schwersten Arbeiten (zu Urbarmachungen, Kanalbauten, Errichtung von Hafenanlagen an der Eismeerküste, in Bergwerke usw.) hinausgeschickt. Ebenso war die Zwangsinternierung in der Hitlerdiktatur, die von Cestapo, SS und SD vollzogen und verwaltet wurde, gekennzeichnet durch Zwangsarbeit. Im Gegensatz hierzu war das Dasein der deutschen Internierten in den KZ's der NKWD seit 1945 bestimmt durch Beschäftigungslosigkeit und durch das erstmals hier konsequent angewandte System der Distrophie.

Nach dem Vergleich der sowjetischen und deutschen Konzentrationslager ging Birkenfeld ausdrücklich auf die Lager in der sowjetischen Besatzungszone ein:

Im Sommer 1946 bestanden im sowjetisch besetzten deutschen Gebiet die folgenden Zwangslager mit KZ-Charakter: Buchenwald bei Weimar, Sachsenhausen bei Oranienburg, Bautzen, Torgau, Fünfeichen bei Neubrandenburg, Mühlberg, Hohenschönhausen, Jamlitz bei Lieberose, Landsberg an der Warthe, Weesow bei Werneuchen, ferner einige kleinere Lager und Gefängnisse. Davon bestanden bereits im SS-Staat als KZ's: Buchenwald, Sachsenhausen, Neubrandenburg. Die Baracken und Lagereinrichtungen wurden so übernommen, wie man sie nach der Besetzung vorfand. Die wichtigste Neuerung, die von der NKWD eingeführt wurde, war die Einteilung in Lager-Zonen (getrennt für Strafgefangene und politische Internierte) und die Absperrung jeder einzelnen Baracke durch einen Stacheldrahtzaun. Weitere wesentliche Unterschiede werden aus den nachfolgenden Ausführungen hinreichend erkenntlich. Bautzen und Torgau waren alte Gefängnisse beziehungsweise Zuchthäuser, Jamlitz ein SS-Straflager, Mühlberg ein Kriegsgefangenenlager. Weesow war kein festes Lager, vielmehr wurden die weiblichen und männlichen Internierten in den Ställen und Scheunen des Dorfes zusammengepfercht. ${ }^{461}$

Birkenfelds Ausführungen im Zusammenhang seiner Untersuchung über das gesamte NKWD-Lagersystem in der sowjetischen Besatzungszone enthielten genaue Informationen. Zu einem Zeitpunkt, wo noch keine genuine Forschungsliteratur existierte, vermittelten seine Ausführungen ausdrückliche Hinweise darüber, welche Lager vom "SS-Staat« übernommen wurden, und hob die speziellen Unterschiede der einzelnen Lager des "NKWD-Staates" heraus. Im Grunde genommen stellten ebendiese Ausführungen des Verfassers eine genaue Typologie der NKWD-Lager in Ostdeutschland dar. ${ }^{462}$ Vor diesem Hintergrund kam Birkenfeld auf der Grundlage seiner Quellen auf qualitative und quantitative Aspekte zu sprechen. Das heißt, der Autor nannte zum einen ausdrücklich die (geschätzte) Anzahl der Gefangenen für das Lagersystem und

461 Ebd.; S. 630.

462 Vgl. hierzu auch: Konzentrationslager in der Sowjetzone, in: Ost-Probleme 2 (1950), Nr. 30, S. 957960 . 
ging zum anderen auf das »Schicksal« der Häftlinge und auf die »Geschichte« einzelner Lager ein. »Im Februar 1949«, so Birkenfeld,

veröffentlichte die »Kampfgruppe« eine erste Statistik, die nach dem Mosaiksystem, aus den übereinstimmenden Aussagen von mindestens drei ehemaligen Häftlingen, zusammengestellt wurde. Für die politisch Internierten, also ausschließlich [die] Strafgefangenen, ergab sich damals eine Gesamtzahl von 231 ०००. Davon sollten zu jenem Zeitpunkt verstorben sein: 101800 , nach der Sowjetunion deportiert: 40 800, entlassen: 29 000, noch in Internierung: 59 400. Nach den inzwischen fortgesetzten Erhebungen dürften alle diese Zahlen etwas zu hoch sein. Am 15. Januar 1950 hatte die »Kampfgruppe« einwandfrei insgesamt $180000 \mathrm{KZ}-\mathrm{Häftlinge} \mathrm{ermittelt,} \mathrm{von} \mathrm{denen}$ 96000 in den Lagern verstorben waren.

In der ersten Statistik der »Kampfgruppe« fehlte das KZ Ketschendorf, eines der berüchtigsten Lager [...]. Dort waren bereits Ende Mai 1945 nahezu 10 ooo deutsche Internierte und mehrere hundert Ausländer, deren Zahl sich im Laufe des Jahres auf ungefähr 2000 erhöhte. Unter ihnen befanden sich viele »Wlassow«-Russen und Ukrainer, ferner etwa 110 Ausländer anderer Nationalitäten. Die Zivilrussen wurden im Februar 1946 bis auf einen kleinen Rest nach der Sowjetunion abtransportiert. Die anderen Nationalitäten wurden zuletzt nach Buchenwald verlegt, die deutschen Häftlinge zunächst nach Neubrandenburg und später gleichfalls nach Buchenwald. Auch das Lager Mühlberg ging im September 1948 in Buchenwald auf.

Am 15. Januar 1950 bestanden noch die KZ's Buchenwald mit 11 ooo Zivilinternierten; Sachsenhausen mit 3000 Zivilinternierten und 13600 Strafgefangenen; Bautzen (früher Militär-Zuchthaus) mit 1050 Zivilinternierten (unter ihnen zahlreiche noch nicht Verurteilte) und 5500 Strafgefangenen. ${ }^{463}$

Bemerkenswert an diesen Ausführungen von Birkenfeld seiner »kleinen Studie« war, dass sie detaillierte Angaben über die Anzahl der »politischen Internierten« enthielt die natürlich aufgrund der »Archivsituation « und fehlender Forschungsliteratur nur geschätzte Zahlen waren - und zudem darüber informierte, wie sich die Zahl der (deutschen und nichtdeutschen) Gefangenen im Laufe der Zeit veränderte: zum Beispiel durch den Tod von Häftlingen oder dadurch, dass Häftlinge in die Sowjetunion deportiert wurden. Wichtig war auch sein Hinweis darauf, dass sich im System der NKWD-Lager im Januar 1950 insofern eine zentrale Veränderung ergab, als einige Lager geschlossen wurden und »nur« noch die Konzentrationslager Buchenwald, Sachsenhausen und Bautzen existierten.

Im weiteren Verlauf seiner Studie über den »NKWD-Staat« ging Birkenfeld neben der von der sowjetischen Regierung im Januar angeordneten Auflösung ebendieser drei Konzentrationslager ${ }^{464}$ ausführlich auf die konkrete Situation der Häftlinge in erster Linie in Buchenwald und Sachsenhausen ein. Das heißt, im Zusammenhang seiner Analyse des sich in drei Abschnitte unterteilten »Vernichtungsprozesses« (Birkenfeld) in den Lagern beschrieb er die komplexe Terrorrealität, unter der die Gefangenen nach ihrer Verhaftung leben mussten und die in zahlreichen Fällen unter anderem aufgrund der Verpflegungssituation und generellen Versorgungsbedingungen im

463 Günther Birkenfeld, Der NKWD-Staat, in: Der Monat 2 (1950), H. 18, S. 628-643, hier S. 630 f.

464 Ebd., S. 631. 
»NKWD-Staat« zum Tod führten. In diesem Zusammenhang stellte er einen weiteren Vergleich zwischen den nationalsozialistischen und sowjetischen Konzentrationslagern an - mit einem ausdrücklichen Verweis auf die Studie Der SS-Staat von Eugen Kogon - und beleuchtete beispielsweise auch die Lagerhierarchie unter den Häftlingen. ${ }^{465}$

In der Sowjetunion verschärfte sich die politische Situation nach dem Zweiten Weltkrieg sehr schnell. Insbesondere die in Gang kommende Säuberung führender Militäroffiziere der siegreichen und in der Bevölkerung überaus populären sowjetischen Armee - unter anderem wurde der einen »überragenden Ruf genießende Marschall Schukow abgesetzt und degradiert - und die 1947 einsetzende generelle Säuberung der Armee wies Parallelen zu den späten 1930er-Jahren auf, zumal auch Teile der Bevölkerung von staatlichen Terrormaßnahmen betroffen waren. Allerdings verzichtete die stalinistische Führung darauf, öffentliche Schauprozesse zu inszenieren. Der repressive Herrschaftscharakter zeigte sich auch in anderen Bereichen, als sich nämlich ein scharfer Kurs auch in der kommunistischen Kulturpolitik im Allgemeinen und gegenüber den sowjetischen Intellektuellen im Besonderen bemerkbar machte. Schdanow blies in seiner Rede vor dem Zentralkomitee der Partei im September 1946 zum Angriff und verkündete den Kulturkampf. Nach außen stellte diese Rede eine »ideologische Kriegserklärung « an die westlichen demokratisch-kapitalistischen Staaten und nach innen eine Disziplinierung und Knebelung der Geistesfreiheit dar. In der Folge wurden Wissenschaftler, Dichter und Künstler - wie zum Beispiel der Philosoph Alexandrow, der Nationalökonom Warga oder der Komponist Schostakowitsch - zur Rechenschaft gezogen, weil sie sich »objektivistischer, formalistischer oder kosmopolitischer Tendenzen" schuldig gemacht hatten und durch eine quasi Verherrlichung der »dekadenten bürgerlichen Kultur« in den Augen des stalinschen Politibüros »Verrat« an der Partei und am sowjetischen Staat begangen hatten. ${ }^{466}$ In diesem "neuen« Kurs brach sich vor dem Hintergrund eines verstärkt grassierenden russischen Nationalismus und der damit verbundenen Verklärung des slawischen Ursprungs der Russen die chauvinistische Verherrlichung russischer Kulturleistungen Bahn. In der Naturwissenschaft setzte Stalin persönlich durch, dass die Theorie des Biologen T. D. Lyssenko allein Gültigkeit besaß - Lyssenko entwickelte die Theorie von der Veränderlichkeit des Erbgutes durch äußere Einwirkung - und eine dogmatische Monopolstellung erlangte und nicht nur der "wissenschaftlichen Freiheit" ein Ende bereitete, sondern auch die Säuberung von »un-sowjetischen« Wissenschaftlern zur Folge hatte. ${ }^{467}$

Nach dem Tod des Leningrader Parteiführers Schdanow Ende August 1948 wurde eine erneute politische Terrorwelle von Stalin in der Sowjetunion in Gang gesetzt, von der nicht nur die Bevölkerung betroffen war, sondern die sich in erster Linie gegen die Partei richtete. Insbesondere führende Funktionäre des Leningrader Parteiappa-

465 Siehe im Einzelnen ebd., S. 631-643. Darauf gehe ich in Kap. IV.3.3 ein.

466 Vgl hierzu mit dem Schwerpunkt auf der Kunst im Allgemeinen und der Literatur im Besonderen liegenden Beitrag Wladimir Weidlé, Als Rußland noch »kosmopolitisch« war ..., in: Der Monat 4 (1952), H. 45, S. 263-278, sowie speziell für den »Angriff«auf die sowjetische Musik Nikolas Nabokow, Gereinigte Noten. Ein Bericht über das sowjetische Musikleben, in: Der Monat 2 (1949), H. 15, S. 325-327.

467 Vgl. hierzu Bertram D. Wolfe, Der Fall Lyssenko. Das Schicksal der Wissenschaft in der UdSSR, in: Der Monat 1 (1949), H. 8/9, S. 112-119. 
rates waren das Ziel der vom Kremlchef gesteuerten Säuberungsaktion. Die Zahl der allein in der »Leningrader Affäre« - die zum Synonym der zum damaligen Zeitpunkt laufenden Säuberungswelle wurde - verhafteten und größenteils getöteten Parteimitglieder betrug mehrere Hunderte - darunter die beiden prominenten "Spitzenfunktionäre« Nikolaj A. Wosnessenski und dessen Stellvertreter Alexej A. Kusnezow.

Quasi zeitgleich mit der "Zweiten Jeschowschtschina« geriet das stalinistische Herrschaftssystem angesichts der zugespitzten Situation im Kalten Krieg (BerlinBlockade) vor allem durch den Bruch Titos mit Moskau außenpolitisch unter Druck. Zur Vorgeschichte des Bruches: Zwischen der Sowjetunion und Jugoslawien war im April 1945 ein Freundschafts- und Bündnisvertrag abgeschlossen worden, der auf den ersten Blick auch eine ideologische Grundlage zu haben schien. Im Laufe der Zeit zeigte sich allerdings, dass Tito in Bezug auf die jugoslawische Innenpolitik und die Beziehungen der »Balkanländer« untereinander eine spezielle persönliche Bedeutung besaß. Nachdem Tito bereits bei der Unterdrückung aller oppositionellen Parteien des Landes und der Durchführung radikaler wirtschaftlicher und sozialer Reformen einen »eigenen Weg« gewählt hatte, zeigte sich seine Eigeninitiative und sein Ziel nach Unabhängigkeit gegenüber Moskau in seinen Hegemonialbestrebungen in den südosteuropäischen Ländern. Angesichts der seit Sommer 1947 laufenden Erörterungen zwischen Tito und dem bulgarischen Kommunistenführer Dimitrow, die im Kern den Plan einer "Balkanförderation« hatten, sah sich Stalin gezwungen, politisch zu reagieren, und versuchte den Druck auf den gefährlichen Konkurrenten und »Ketzer« zu erhöhen. Die Gründung der Kominform mit dem Sitz in Belgrad war in dem Ziel begründet, die politische Kontrolle über Jugoslawien zu verschärfen. Um den Druck auf Tito zu erhöhen, unterstützte Stalin die mit Moskau sympathisierenden Kräfte in der Kommunisten Partei Jugoslawiens, die daraufhin von Tito verhaftet wurden. Somit war der Bruch nicht mehr zu vermeiden. Im Frühjahr 1948 beorderte Stalin die sowjetische Militärmission aus Belgrad zurück und im Juni desselben Jahres wurde eine »Pressekampagne« gegen Tito gestartet, die schwere Anschuldigungen gegenüber dem »Ketzer« enthielt. Am Ende stand der Ausschluss der Kommunistischen Partei Jugoslawiens aus der Kominform und am 28. Juni 1948 wurde Tito sozusagen offiziell als »Verräter« erklärt. ${ }^{468}$

In der Folgezeit verschärfte der Kremlchef seinen politischen und militärischen Kurs in den osteuropäischen Staaten. Vor dem Hintergrund der Entwicklung in Jugoslawien und des dort eingeschlagenen Weges eines von Moskau unabhängigen Kommunismus, d. h. eines »nationalen Kommunismus«, startete Stalin Ende 1948 eine Terror- bzw. Säuberungswelle in den kommunistischen Parteien in Albanien, Polen, Ungarn, Bulgarien und der Tschechoslowakei, der nicht zuletzt die führenden Funktionäre zum Opfer fielen. Zu den spektakulärsten Fällen zählte die im Juni 1949 vorgenommene Verhaftung einer Gruppe führender Parteimitglieder um den ungarischen Innenminister Lázló Rajk - die im Oktober desselben Jahres aufgrund gefälschten

468 Vgl. hierzu im Einzelnen Ruth Fischer, Tito contra Stalin. Gegenwartsprobleme der Komintern-Strategie, in: Der Monat 1 (1949), H. 7, S. 44-57, sowie unter dem Aspekt des Bruchs zwischen Stalin und Tito mit speziellen Ausführungen zu den Unterschieden zwischen dem stalinistischen und »titoistischen« Herrschaftssystem die Beiträge Melvin ]. Lasky, Balkan-Tagebuch. Notizen von einer Reise nach Jugoslawien, in: Der Monat 4 (1951), H. 39, S. 261-269, sowie den zweiten Teil, in: Der Monat 4 (1952), H. 40, S. 345-356; Richard Löwenthal, Brief aus Belgrad: Titos »Croßes Experiment«. Ein Bericht aus dem neuen Jugoslawien, in: Der Monat 5 (1952), H. 49, S. 39-49. 
Beweismaterials und erpresster Geständnisse umgebracht wurden - sowie zum anderen der Ausschluss des führenden bulgarischen Kommunisten Trajtscho Kostow aus dem Politbüro und dem Zentralkommitee der KP Bulgariens im März 1949, der im Dezember desselben Jahres nach der Verhaftung erhängt wurde. In der polnischen Hauptstadt Warschau fand Anfang Juni 1950 ein Prozess gegen eine Gruppe führender Funktionäre um den General Tatar statt, der mit harten Strafen für die Angeklagten endete. Der Prozess war von der »Stalin-Clique« als Vorspiel gedacht für einen geplanten Prozess gegen den kommunistischen Parteiführer Gomulka und gegen weitere zahlreiche Funktionäre (die Verhafteten überlebten den Terror durch den Tod Stalins).

Das stärkste Interesse und das größte Entsetzen in der zeitgenössischen internationalen Öffentlichkeit löste allerdings der öffentliche Schauprozess gegen den führenden tschechoslowakischen Kommunisten Rudolf Slánský aus, der nach einem vergleichbaren Muster wie die drei "großen« Moskauer Prozesse ablief (Geständnisse, Selbstbezichtungen der Angeklagten etc.) und mithin unweigerlich Erinnerungen an die Jahre des »Großen Terrors« auslöste. Mit dem Generalsekretär des ZK der KP der Tschechoslowakei wurden weitere prominente Parteiführer auf der Grundlage gefälschten Materials zu Agenten gestempelt und im November 1952 entweder zum Tode verurteilt oder - wie zum Beispiel Arthur London - zu lebenslanger Haft verurteilt. Das spektakuläre des Prager Schauprozesses war allerdings vor allem die eindeutig antisemitische Stoßrichtung, da Slánský und weitere Angeklagte auch als »Juden« bzw. als »zionistische Agenten« verurteilt wurden.

Die Säuberungswelle in den Ländern Osteuropas bzw. in den »Volksdemokratien« war für die Zeitgenossen freilich ein Indikator für einen »neuen Kurs« von Stalin. In den kommunistischen Parteien der einzelnen Länder wurden die »alten Kader«abgesetzt und in vielen Fällen liquidiert, womit ihr politischer Einfluss auf die Staatsführung verhindert wurde. Dafür wurden »Mini-Stalins« installiert - Bierut in Polen, Gottwald in der Tschechoslowakei oder Rákosi in Ungarn -, die bedingungslos die politischen Maßnahmen Moskaus umsetzten und für das Funktionieren des Systems in den »Satellitenländern « verantwortlich waren. Aber auch in den kommunistischen Parteien in den westeuropäischen Ländern brach sich die neue (außen-)politische Linie Moskaus Bahn. Beispielsweise wurde in zeitlicher Koinzidenz zum Prager »SlánskýSchauprozess « Ende 1952/Anfang 1953 in Paris ein öffentlicher (Schau-)Prozess en miniature gegen den führenden Funktionär der Kommunistischen Partei Frankreichs und - laut »Anklageschrift« - »Fraktionisten « und »Verräter « André Marty in Gang gebracht. Wie in Prag bezichtigte sich der von der Partei angeklagte ehemalige »Spanienkämpfer« und »hundertfünfzigprozentige Stalinist« (Lüthy) aller ihm zur Last gelegten Verbrechen. ${ }^{469}$

In der Sowjetunion radikalisierte sich die innenpolitische Lage Ende der 1940erund zu Beginn der 1950er-Jahre. Stalin setzte vor dem Hintergrund der »Leningrader Affäre « und des grassierenden russischen Nationalismus und Chauvinismus unter anderem eine antisemitische bzw. antizionistische Kampagne in Gang, die sich gezielt gegen jüdische Intellektuelle, Künstler und Gruppen (zum Beispiel Mitglieder des Jüdischen Antifaschistischen Komitees) richtete. Der stalinistische Antisemitis-

469 Zu den Einzelheiten und den historisch-politischen Parallelen zwischen den Schauprozessen in Prag und Paris vgl. die Beschreibung und die analytischen Reflexionen von Herbert Lüthy, Prag, Paris und Paranoia, in: Der Monat 5 (1953), H. 52, S. 444-446. 
mus, der sich auch und vor allem im »Slánský-Schauprozess« niederschlug, wies in den Augen der interessierten Zeitgenossen zweifelsohne Parallelen und Analogien zum "nationalsozialistischen und hitlerschen Antisemitismus « auf. ${ }^{470}$ Ihren negativen Höhepunkt fand die antisemitische bzw. antizionistische Kampagne in der Sowjetunion unter Stalin in der »Ärzte-Verschwörung«, die von ihm im Winter 1952/53 in Gang gesetzt wurde. Fünf prominenten Ärzten wurde vorgeworfen, »zionistische Agenten«, »Spione des Westens« und der »Kopf « einer Verschwörung zu sein, die zum einen für den Tod führender Mitglieder der Partei verantwortlich waren (unter anderem wurde ihnen vorgeworfen, Schdanow ermordet zu haben) und zum anderen das Ziel hatten, Stalin zu vergiften. Die Verhaftung der »Mordärzte« und die Aufdeckung des »Ärztekomplottes« war kurz vor dem Tod Stalins der Auftakt für eine umfassende Säuberung der Sicherheitsapparate, der Partei und des Politbüros, von der auch die engsten Gefährten des Kremlchefs betroffen waren - wie zum Beispiel Molotow oder Mikojan.

Noch bevor Stalin starb, setzte sich der international bekannte Renegat und Kommunismusexperte Richard Löwenthal im Monat sowohl mit den - oben in aller Kürze angesprochenen - zurückliegenden Entwicklungen Ende 1940/Anfang 1950 sowie der terroristischen Politik Stalins 1952/53 in der Sowjetunion, in den osteuropäischen Satellitenstaaten und in der Französischen KP (sowie mit der Entwicklung in China) auseinander. In seinem im Märzheft des Jahres 1953 veröffentlichten Beitrag Der Hintergrund der Säuberung versuchte Löwenthal die historisch komplexe (Terror-)Politik Stalins zu interpretieren und $\mathrm{zu}$ analysieren. ${ }^{471}$ Im Folgenden wird die Veröffentlichung von Löwenthal aufgrund des genuin analytischen Anspruchs fast in Gänze wiedergegeben - damit der Kommunismusexperte zum einen ausführlich persönlich zu »Wort« kommen und zum anderen das empirische Material der Zeitschrift von »selbst sprechen« kann. Im Anschluss daran erfolgt vor dem Hintergrund der zeitgenössischen Forschungserkenntnisse zur Geschichte des Sowjetkommunismus ein Kommentar.

Steckt hinter dem scheinbaren Wahnsinn der Säuberungen, die gegenwärtig den kommunistischen Teil der Welt erschüttern, eine verborgene Methode? Können wir hinter dem Wust absurder Beschuldigungen und noch absurderer Ceständnisse, die von Bukarest bis Berlin und von Prag bis Moskau die Atmosphäre verpesten, einen rationellen politischen Zweck erkennen?

Mit diesen Worten begann Löwenthal seinen sich auf fünf Zeitschriftenseiten erstreckenden Beitrag, um wie folgt fortzufahren:

Es ist, als sähen wir verschwommen, wie hinter einem dunklen Fenster, die Gestalten einiger der sowjetischen Machthaber in einem Kampf auf Tod und Leben miteinander ringen. Viel mag davon abhängen, daß wir erkennen, wer gegen wen kämpft und um welche Streitfragen - welche Politik die »Cesäuberten«, welche die »Säuberer«vertreten. Gibt es ein Mittel, das herauszufinden?

470 So exemplarisch Herbert Lüthy, ebd., S. 446.

471 Richard Löwenthal, Der Hintergrund der Säuberung, in: Der Monat 5 (1953), H. 54, S. $672-676$. 
Die jüngsten Ereignisse haben uns drei Anhaltspunkte geliefert, die auf den inneren Zusammenhang hinzudeuten scheinen. Erstens nimmt die Große Säuberung ihren Weg von der äußeren Peripherie des stalinistischen Apparats zum Mittelpunkt hin. Die Anklage im Prager Slansky-Prozeß gegen eine Reihe wichtiger direkter Agenten des sowjetischen Sicherheits- und Spionagedienstes und der Ausschluß von kommunistischen Führern wie André Marty, die lange von höchster sowjetischer Stelle gedeckt worden waren, führten einige Beobachter zuerst zu dem Schluß, daß Erschütterungen dieser Art auch in der Sowjetunion selbst zu erwarten seien.

Zweitens wird zwar behauptet, daß die Kontakte zwischen den verurteilten »Spionen und Verrätern « in den Satellitenländern und den Geheimdiensten des Westens über die verschiedensten Kanäle liefen - durch zionistische und andere jüdische Organisationen, durch westliche Korrespondenten, selbst bekannte Mitläufer im Westen - doch das Ziel ihrer »Verschwörungen « wird in jedem Fall als ein »titoistischer Staatsstreich« bezeichnet: als ein Versuch, die Satellitenstaaten der russischen Vormundschaft zu entreißen.

Drittens hat die Sowjetpresse unmittelbar vor der Aufdeckung der»Ärzteverschwörung im Kreml « den ersten offenen Angriff auf den ehemaligen Vorsitzenden der staatlichen Planungskommission, A. N. Wosnessenskij, veröffentlicht. Bis zu seiner öffentlich nie begründeten Amtsenthebung im Jahre 1949 hatte dieser als einer der Hauptbefürworter einer Außenpolitik der Offensive innerhalb des Politbüros gegolten: in seinem Buch über die sowjetischen Kriegsleistungen, das jetzt als »antimarxistisch« verurteilt wird, hatte er behauptet, das Kriegspotential der Sowjetunion und der Satellitenstaaten zusammen sei bereits dem des Westens überlegen, und so den Schluß nahegelegt, Sowjetrußland könne ungestraft einen neuen Weltkrieg riskieren. ${ }^{472}$

Für Löwenthal ging die erste "große Moskauer Säuberung« aus den Jahren 1936 bis 1938 auf die "furchtbaren Kämpfe der Jahre 1929 bis 1931« zurück, also auf den Beginn des ersten Fünfjahresplans, die Zwangskollektivierung und die Hungersnot, und für ihn hatte es damals den Anschein, dass »die Säuberungswelle, die sich heute ausbreitet«, so Löwenthal,

mit den kritischen Entscheidungen der Jahre 1948/49 im Zusammenhang zu stehen dem Bruch mit Tito, dem totalen Sieg Mao Tsetungs in China und den ersten ernsten Rückschlägen für den kommunistischen Vormarsch in Europa. Jene Entscheidungen warfen das immer wiederkehrende Crundproblem der sowjetischen Strategie auf: wann muß man von der äußeren Expansion der kommunistischen Revolution auf ihre Intensivierung im Innern umschalten; vom Angriff zur Konsolidierung übergehen; im Verschlingen eine Pause machen, um erst einmal zu verdauen.

Denn die Machthaber Rußlands leben, trotz ihrer Verwerfung von Trotzkis Person und Lehre, noch immer nach dem Cesetz der permanenten Revolution - nur ist es jetzt eine von oben gelenkte Revolution, deren Triebkraft die Macht des totalitären Staatsapparates ist. Im Gegensatz zu jeder bürokratischen Kaste, die die bisherige Geschichte kennt, ist Stalins Parteibürokratie nicht konservativ geworden und kann es nicht werden: sie hält sich nicht dadurch an der Macht, daß sie das Bestehende stabilisiert, sondern gerade dadurch, daß sie ihre Untertanen nie zur Ruhe kommen läßt. 
Stalins letzte Abhandlung, die im vergangenen Oktober am Vorabend des 19. Kongresses der Kommunistischen Partei der Sowjetunion veröffentlicht wurde, läßt sich am besten als Wegweiser für diese permanente Revolution von oben verstehen. Diese Revolution kann während langer Zeitabschnitte durch innere Umwälzungen fortschreiten, mit der Entwurzelung von Millionen durch Zwangskollektivierung, mit industriellen Riesenbauten, Massendeportationen und Zwangsarbeit; wenn sich dann Gelegenheit zu Eroberungen bietet oder der Zusammenbruch von Nachbarstaaten ein politisches Vakuum schafft, wird der äußere Machtbereich erweitert, werden Satellitenregierungen errichtet; dann wiederum werden dieselben Stufen gesellschaftlicher Umwälzung in den neugewonnenen Cebieten durchlaufen, während im Kernland der Revolution noch weitergehende Schritte unternommen werden. Die Wendepunkte im Auf und Ab dieses revolutionären Prozesses sind immer Augenblicke der Spannung, des Zweifels, der inneren Auseinandersetzungen und der akuten Krise.

Der bis dahin letzte große Wendepunkt dieser Art wurde für den Mitarbeiter des Monat 1948/49 erreicht. Denn, so führte Löwenthal aus:

Die sowjetische Nachkriegsexpansion hatte begonnen, auf ernsten westlichen Widerstand zu stoßen - in Criechenland, in Cestalt der Berliner Luftbrücke, in der Stabilisierung Westeuropas durch den Marshallplan. Die Entscheidung für oder gegen das Wagnis eines allgemeinen Krieges wurde unvermeidlich. Und gleichzeitig entdeckten die sowjetischen Führer plötzlich, daß ihre politischen Verbindungslinien bereits bedenklich dünn geworden waren - daß während der Zeit der Tatenlosigkeit des Westens der kommunistische Machtbereich zu schnell erweitert worden war, um noch mit Sicherheit von seinem Zentrum in Moskau kontrolliert werden zu können. Der erfolgreiche Abfall Titos 1948 und die Eroberung ganz Chinas durch Mao 1949 haben die Aufmerksamkeit der Sowjets auf diese Gefahr gelenkt, und haben dadurch wahrscheinlich ebensoviel wie der Widerstand des Westens dazu beigetragen, die sowjetische Expansion zeitweilig zum Halten zu bringen.

Um die Tiefe und Nachhaltigkeit der durch die Tito-Affäre im ganzen sowjetischen Machtbereich ausgelösten Rückwirkungen zu verstehen, muß man bedenken, daß Titos Ausbruch weit mehr als ein lokales Ereignis war: er kennzeichnete das Scheitern des großen Experiments der sowjetischen Nachkriegspolitik, das die Befürworter fortgesetzter hemmungsloser Expansion im Politbüro durchgeführt hatten - des Versuchs, die kommunistische Expansion zu beschleunigen, indem man den militantesten neuen kommunistischen Regierungen außerhalb der Sowjetunion eine gewisse eigene Initiative zugestand.

Das Organ dieses Experiments war das Kominform-Büro, 1947 mit dem Sitz in Belgrad gegründet und auf dem Prinzip aufgebaut, daß Anweisungen für die mächtigsten kommunistischen Parteien des Westens - die französische und italienische - über die europäischen »Volksdemokratien« laufen sollten, deren kommunistische Führer denen des Westens psychologisch näher standen als die Russen. Sein Vater war Andrej Alexandrowitsch Shdanow, damals erster Sekretär der Kommunistischen Partei der Sowjetunion unter Stalin und nach allgemeiner Ansicht vermutlich sein Nachfolger. Seine Theorie war - nach seinen eigenen Worten bei der Gründungstagung der Kominform -, daß die Hauptgefahr für die Kommunisten jetzt darin bestehe, die Stärke ihrer Feinde zu überschätzen und die eigene Stärke zu unterschätzen - anders 
ausgedrückt, daß kühne Offensive die beste Strategie sei. Und der hervorragendste Exponent des ganzen Versuchs war kein anderer als Tito, damals der militanteste kommunistische Führer Osteuropas - der erste, der in seinem Staat ein vollständiges Einparteienregime schuf, der erste, der die zögernden Kommunisten des Westens als opportunistische Schwächlinge angriff [...]. ${ }^{473}$

Nach Auffassung von Löwenthal erreichte das `Experiment< seinen Höhepunkt, als um die Jahreswende 1947/48 Tito eine »triumphale Rundreise« durch sämtliche Hauptstädte der »Volksdemokratien « machte. Indes: Vor dem Hintergrund der Absicht von Tito, eine "Balkanförderation« ins Leben zu rufen, die zweifelsohne für Moskau zu einem »rivalisierenden Zentrum des Kommunismus« geworden wäre, wurde Georgi Dimitrow vonseiten Stalins dazu gezwungen, von Tito abzurücken. Daraufhin startete Moskau seinen >Angriff a a den jugoslawischen Staatschef und die kommunistische Partei des Landes. Im Sommer 1948 wurde Löwenthal zufolge Tito vom KominformBüro ausgeschlossen. "Zwei Monat später verstarb Schdanow - eines natürlichen Todes nach der offiziellen Version von damals, ermordet von den Kreml-Ärzten nach der von heute.« Dass »Tito es wagte«, so Löwenthal,

den Zorn des Kreml zu trotzen, daß er tatsächlich vermochte, seine Partei und seinen Staat zusammenzuhalten, muß für die sowjetischen Führer ein ungeheurer Schock gewesen sein. Hier war der endgültige Beweis, wie bedenkenlos die Shdanowsche Politik nicht nur das Risiko eines Krieges, sondern das einer Befreiung der Satelliten heraufbeschworen hatte. Sogleich begann eine panische Verschärfung der Kontrollmaßnahmen und ein wildes Suchen nach potentiellen Titos, um sie rechtzeitig zu liquidieren.

Rajk in Ungarn, Kostoff in Bulgarien, Dsodse in Albanien wurden als »Verräter« verurteilt und gehängt; Comulka in Polen wurde abgesetzt und später verhaftet; der griechische Partisanenführer General Markos verschwand noch vor der Beendigung des Bürgerkrieges. Die vorher gültige These, daß jede kommunistische Partei das Recht habe, gleich Tito gemäß den eigenen nationalen Bedingungen einen eigenen, nichtrussischen Weg zur Macht zu finden, wurde als ketzerisch verdammt. Der Aufbau des Kominform-Apparats selbst wurde jetzt als nachweislich falsch angesehen: für einen Satellitenführer wurde es jetzt gefährlich, wenn er jemals geheime Verbindungen zum Westen gehabt hatte - auch dann, wenn es sich um Kontakte mit westlichen Kommunisten oder bekannten Mitläufern handelte, die er im Auftrag des Kominform wahrnahm.

Auch die Verbindungen, die Kommunisten während des Krieges mit sowjetischer Billigung und zu Rußlands großem Vorteil mit westalliierten Dienststellen angeknüpft hatten, wurden jetzt nicht nur zum Vorwand genommen, um ohnehin in Ungnade gefallene und kompromittierte Persönlichkeiten zu entfernen, sondern wurden tatsächlich als potentielle Gefahrenquellen für die Sowjetunion angesehen. Der amerikanische Kommunist Noel Field z. B. wurde 1949 irgendwo hinter dem Eisernen Vorhang verhaftet und seither in allen Schauprozessen als gefährlicher westlicher Agent erwähnt; und Dutzende von führenden Mitgliedern des kommunistischen Geheimapparats in ganz Europa, die jetzt aus solchen Cründen als »infiziert« galten, wurden in den folgenden 
Jahren entweder nach Osten gelockt und dort verhaftet oder auch bei der westlichen Polizei denunziert. ${ }^{474}$

Im Anschluss an diese Ausführungen ging Löwenthal in seinem Beitrag Der Hintergrund der Säuberungen, der in der Märzausgabe 1953 des Monat erschien, zuerst auf die innenpolitische Situation in der Sowjetunion Ende der 1940er-Jahre ein und danach auf die - nach einer »Terror-Pause« Anfang der 1950er-Jahre - in den Monaten vor dem Tod Stalins wieder in Gang gekommenen stalinistischen Säuberungen in den Satellitenstaaten sowie in der Sowjetunion. Hierzu schrieb er:

In der Sowjetunion selbst folgte dem Tode Shdanows alsbald die Absetzung vieler von ihm ernannter Funktionäre und 1949 das stille Verschwinden Wosnessenskijs, der mit seiner These vom überlegenen Kriegspotential der kommunistischen Welt wohl Shdanows wichtigster Verbündeter im Politbüro gewesen war. Wir wissen jetzt aus den letzten Moskauer Angriffen, daß Wosnessenskij schon damals aus der Partei ausgeschlossen worden sein muß. Der jetzt veröffentlichte Beschluß des Zentralkommitees aus dem Jahr 1949 bezeichnet ihn nicht mehr als »Cenossen«. Damals wurde jedoch keine öffentliche Begründung für sein Ausscheiden gegeben. Das russische Volk erfuhr von keinem Konflikt über Fragen der kommunistischen Weltstrategie, und Anfang 1950 schien die ganze internationale Säuberung einzuschlafen. Nur in der Tschechoslowakei rumorte sie durch die Jahre 1950 und 1951 halb unterirdisch weiter - um dann in den letzten Monaten in einem Land nach dem anderen mit voller Kraft wieder sichtbar zu werden und schließlich in Rußland selbst explosionsartig zum Durchbruch zu kommen. ${ }^{475}$

In diesem Zusammenhang suchte Löwenthal nach einer Erklärung für das für die Zeitgenossen rätselhafte Phänomen der stalinistischen Säuberungen und vertrat folgenden Standpunkt:

Wenn wir eine Erklärung dafür finden können, warum die Säuberung zeitweise unterbrochen wurde und warum nur die jetzige zweite Welle zu öffentlichen Anklagen in Sowjetrußland selbst geführt hat, dann haben wir vielleicht den Schlüssel zu dem ganzen Rätsel in der Hand. Die logisch einleuchtendste Erklärung ist wohl, daß die Liquidierung von Shdanows politischem Erbe zwei verschiedene, wenn auch eng zusammenhängende politische Fragen aufrollte: erstens die Verhinderung weiterer »TitoKrisen« durch verschärfte Kontrolle der Satelliten und Abruch gefährlicher Westkontakte; zweitens die Ersetzung von Shdanows Offensiv-Strategie durch eine neue Politik gegenüber dem Westen.

Es scheint heute klar, daß sich die sowjetischen Führer über den ersten Punkt schon 1949 völlig und endgültig geeinigt hatten. Aber der Angriff auf Südkorea im Sommer 1950 und die seither zutage getretene Uneinheitlichkeit der sowjetischen Außenpolitik deuten darauf hin, daß keine entsprechende Übereinstimmung in der zweiten Frage bestand. Nach dieser Lesart würde die zweite Welle der Säuberung die bevorstehende zweite Entscheidung ankündigen - den Entschluß, die gefahrvolle Expansionspolitik 
für eine gewisse Zeit aufzugeben und die Hauptenergien des Kreml einstweilen den nächsten Stufen der inneren Revolution in den europäischen Satellitenländern und in China zu widmen. ${ }^{476}$

Nach dem Dafürhalten von Löwenthal gab es aufgrund der damaligen »Tatsachen« sozusagen stichhaltige Anhaltspunkte für seine Interpretation der stalinistischen Säuberungen. Denn, so der Autor:

In Rußlands europäischen Kolonien ist seit der Ausmerzung der angeblich »titoistischen« Führer das Tempo der Kollektivierung der Landwirtschaft und des forcierten Aufbaus der Schwerindustrie nach sowjetischen Muster erheblich gesteigert worden; in den letzten paar Monaten hat es sich weiter beschleunigt. Aber die eindrucksvollste Bestätigung, daß Rußland sich nun ernstlich auf die Aufgabe konzentriert, die vom Kommunismus neu eroberten Länder gleichzuschalten und zu verdauen, kommt aus China.

Löwenthal zufolge hatte China seit 1952 vor dem Hintergrund von Stalins Schrift über die Ökonomischen Probleme des Sozialismus in der UdSSR einen politischen Kurs favorisiert, der sich die sowjetische Gesellschaftsentwicklung zum »Vorbild« genommen hatte und der im Grunde genommen so gedeutet werden konnte, dass das Regime die "gefahrvolle Expansionspolitik für eine gewisse Zeit« ebenfalls aufgegeben hatte. ${ }^{477} \mathrm{Al}-$ lerdings gab es für den Kommunismusexperten noch einen weiteren Ansatzpunkt für seine Deutung der zeitgenössischen stalinistischen Säuberungen:

Schließlich sind die Opfer der zweiten Säuberungswelle in den europäischen Satellitenstaaten großenteils [sic!] Leute wie Slansky und Anna Pauker, die nie die geringste Neigung zu einer unabhängigen nationalen Politik gezeigt haben. Aber sie waren Vertreter einer aggressiven Außenpolitik und enge Verbündete der Befürworter einer solchen Politik in der Sowjetunion; und den Anklagen gegen sie folgte der erste offene Angriff gegen Wosnessenskij in Rußland selbst auf dem Fuße.

Gleichwohl musste man zum damaligen Zeitpunkt Löwenthal zufolge mit Schlüssen auf die Entwicklung der sowjetischen Außenpolitik noch immer vorsichtig sein. »Wir wissen weder«, schrieb er,

wer unter den russischen Führern etwa Shdanows aggressive Politik nach seinem Tode und der Ausschaltung Wosnessenskijs weiter verteidigt hat, noch sind wir sicher, wer die Befürworter einer radikalen Wendung waren und sind - wenn auch viele Zeichen darauf hindeuten, daß Malenkow sie ausführt. Vor allem können wir auch jetzt noch nicht sicher sein, daß eine endgültige Entscheidung gefallen ist. Der vierjährige Aufschub zwischen dem Beginn der Säuberung und dem blutigen Höhepunkt, dem wir uns jetzt nähern, ist deutlicher Beweis für die Stärke des shdanowistischen Widerstandes, und die Wurzeln dieser Stärke sind leicht zu erkennen: das ehrgeizige Rüstungsprogramm auf lange Sicht und der ständige Druck auf immer vollkommenere Formen des Kollektivismus im Sinne Stalins legen dem russischen Volk so schwere Opfer auf, daß

476 Ebd., S. 675

477 Vgl. im Einzelnen ebd., S. 675. 
manchen der Führer der Weg neuer Eroberungen, mit der Aussicht auf Beute, als der leichtere und schmerzlosere erscheinen mag - so lange sie sich einreden können, daß Eroberungen noch ohne Weltkrieg möglich sind.

Es ist noch nicht einmal klar, von welcher Seite die wilden Beschuldigungen gegen die führenden Ärzte der Sowjetregierung erhoben werden. Auf den ersten Blick könnte die Anklage, daß jüdische Ärzte Schdanow ermordet und das Leben von Führern der Sowjetarmee gefährdet haben, wie ein Gegenschlag sschdanowistischer Elemente der Generalität gegen die verhaßte sjüdische Geheimpolizei< aussehen, die seinerzeit ihre Pläne vereitelte. Doch ebensogut können wir es mit einem zynischen Meisterstück Stalins zu tun haben, dazu bestimmt, die überlebenden Anhänger Shdanows als Anstifter seiner Ermordung vor Gericht zu stellen. Wir werden es nicht wissen, bis auf dem dramatischen Höhepunkt der Säuberung der vorbestimmte Hauptverbrecher enthüllt worden ist. ${ }^{478}$

Vor dem Hintergrund seiner bisherigen Ausführungen stellte sich für Löwenthal noch eine »letzte Frage«. »Wenn es wahr ist«, so der Autor zum Schluss seines Beitrages,

daß es letzten Endes um ernste politische Probleme geht, warum werden sie dann mit Hilfe von so phantastischen Anschuldigungen entschieden? Ist es nicht völlig abwegig, eine rationelle politische Erklärung für einen Vorgang zu suchen, der offensichtlich einen neuen furchtbaren Rückfall in das magische Denken der Primitiven, einen neuen Ausbruch kollektiver Paranoia bezeichnet?

Ich glaube, die Antwort darauf muß sein, daß die Anklagen zwar bewußt darauf berechnet sind, die Tendenzen unserer Zeit zum Massenwahn auszubeuten, daß sie selbst aber nicht einem pathologischen Ceisteszustand, sondern der inneren Logik der kommunistischen Diktatur entspringen. Der Wahnsinn der Schauprozesse ist geradezu das notwendige Gegenstück zu dem Anspruch auf absolute Rationalität.

Erinnern wir uns, daß die sowjetischen Machthaber behaupten, eine wissenschaftlich beweisbare Lehre von der gesellschaftlichen und staatlichen Entwicklung zu besitzen, von der man jeden überzeugen könne, der nicht durch sein reaktionäres Klasseninteresse verblendet sei. Sie geben gleichzeitig vor, sie hätten in der Sowjetunion alle Klassengegensätze abgeschafft und die gewaltsamen Umwälzungen, denen das Leben der Sowjetbürger ständig unterworfen wird, fänden in deren eigenem, einsehbarem Interesse und unter Zustimmung der Opfer statt: in der fiktiven Harmonie dieser pseudorationalen Diktatur gibt es weder Raum für Interessengegensätze noch für bleibende Meinungsverschiedenheiten zwischen Menschen, die das Ziel des Ganzen bejahen. In der Wirklichkeit jedoch sind solche Gegensätze unvermeidlich zwischen Mitgliedern einer Regierung, die für verschiedene Sektoren eines riesigen, differenzierten, von Schwierigkeiten aller Art erschütterten Cesellschaftskörpers verantwortlich sind. Wo solche Konflikte nicht überbrückt werden können, sondern ausgefochten werden müssen, da können sie im Rahmen der offiziellen Doktrin nicht als das dargestellt werden, was sie wirklich sind. Denn es ist unmöglich, dem Volke gegenüber zuzugeben, daß loyale Kommunisten in sachlichen Fragen verschiedener Meinung sein können. Der Konflikt kann nur begriffen werden als eine Manifestation des Bösen, das in ein 
sonst harmonisches System von außen eingedrungen ist - als Frucht der Umtriebe von feindlichen Agenten, von verbrecherischen Spionen, von übelwollenden Ausländern oder von Juden. ${ }^{479}$

Zweifelsohne stellte der in der Märzausgabe des Jahres 1953 erschienene Beitrag Der Hintergrund der Säuberungen von Löwenthal einen substanziellen Versuch dar, die zeitgenössischen stalinistischen Säuberungen $\mathrm{zu}$ analysieren und $\mathrm{zu}$ interpretieren. In diesem Zusammenhang kann grundsätzlich konstatiert werden, dass Löwenthal von einem Totalitarismusbegriff zur Charakterisierung des sowjetischen Kommunismus unter Stalin ausging. In seinen Augen handelte es sich beim Stalinismus um ein historisch neuartiges Herrschaftsregime. Das kommunistische Einparteienregime unterschied sich qualitativ durch das systemimmanente »Gesetz der permanenten Revolution" von traditionellen Herrschaftstypen, genauer gesagt, von der bis zum damaligen Zeitpunkt bekannten »bürokratischen Kaste«. Anders gesprochen: Der totalitäre Herrschaftscharakter des Stalinismus kam dadurch zum Ausdruck, dass "Stalins Parteibürokratie« einem Bewegungsregime glich, dass sich nicht einfach damit zufriedengab, an den Schaltstellen der Macht zu bleiben und mithin ebendiese Macht - klassisch konservativ - zu verteidigen, zu stabilisieren, sondern durch das systemimmanente "Gesetz « besaß es einen dynamischen Charakter und musste gewissermaßen nach »vorne stürmen«. Zudem formulierte Löwenthal in nuce zentrale analytische totalitarismustheoretische Aussagen, die zum einen in der zwei Jahre zuvor erschienenen Totalitarismusstudie von Arendt und zum anderen in der drei Jahre später veröffentlichten Untersuchung The Permanent Purge - Politics in Soviet Totalitarianism von Brzezinski enthalten waren; Brzezinskis Totalitarismusstudie zählte bekanntlich zu den Untersuchungen, die bereits in das Fahrwasser der zeitgenössischen Sowjetkommunismusforschung geraten waren, denn hier dienten die primär anhand des sowjetkommunistischen Regimes gewonnenen Forschungserkenntnisse als Grundlage für generalisierende Aussagen über den Typus der totalitären Herrschaft. ${ }^{480}$

Analog zu den Ausführungen von Arendt in ihrem Kapitel Ideologie und Terror stellte auch Löwenthal - indes ohne ausdrückliche Bezugnahme auf die Totalitarismusstudie - fest, dass die Säuberungen im Allgemeinen und die angesprochenen Schauprozesse im Speziellen mit der Paranoia Stalins oder auch zum Beispiel mit dem "pathologischen Geisteszustand« des sowjetischen Systems nicht hinreichend zu erklären waren. Insistierte Arendt explizit, so Löwenthal implizit auf der »deduktiven Logik« des Terrors und hob folglich das totalitäre Moment der Säuberungen im Kontext der Verbindung von "Ideologie und Terror « im Stalinismus hervor. Wenn man, wie es die sowjetischen Machthaber ohne Zweifel taten, die ideologischen Aussagen der kommunistischen Theorie für »bare Münze«nimmt, wonach sie als Exponenten der Partei Vollstrecker gesellschaftsgeschichtlicher Gesetze sind und vor dem Hintergrund der heilsgeschichtlichen Vorstellungen die erwünschte, die geplante radikale Veränderung der Gesellschaft bzw. eines ganz bestimmten historisch-politischen Zustandes sich nicht realisieren lässt (in Löwenthals Beitrag: das Ziel der sowjetischen Machthaber, die kommunistische außenpolitische Expansion nach dem Zweiten Weltkrieg

479 Ebd., S. 675 f. (Hervorh. des Verf.).

$480 \mathrm{Vgl}$. hierzu die entsprechenden Ausführungen im Einleitungskapitel. 
weiter auszudehnen), dann müssen für einen »überzeugten« Kommunisten zwangsläufig »Feindgruppen« existieren, die die Schuld hatten (bei Löwenthal waren es die »Feinde« in der Partei).

Auf der anderen Seite nahm Löwenthal bereits substanzielle Aussagen der 1956 erschienenen Totalitarismusstudie The Permanent Purge - Politics in Soviet Totalitarianism von Brzezinski vorweg. Demnach handelte es sich beim sowjetischen Kommunismus auch und vor allem um ein totalitäres Herrschaftssystem, weil es nach der erfolgreichen Machtergreifung und der Periode der erfolgreichen Macht das spezielle Ziel verfolgte, die gesamte Gesellschaft zu revolutionieren. Genauer hieß das bei Brzezinski, dass sich das wesentliche Merkmal totalitärer Herrschaft daraus ergab, dass die ökonomische und soziale revolutionäre Umwälzung ausdrücklich von einer ideologisch ausgerichteten und fest organisierten politischen Bewegung angestrebt wurde. Seiner Auffassung nach war dem Anspruch, eine totale gesellschaftliche Revolution herbeizuführen, inhärent, dass sogenannte Spannungen auftreten, die zunächst noch in der Partei durch das Vorhandensein stabilisierender Faktoren und ideologischer Abweichungen verblieben, sich dann allerdings durch die Radikalisierung der Revolution auf die gesamte Gesellschaft ausdehnten. Die sich dadurch für das Herrschaftssystem ergebenden existenziellen Probleme verlangten in den Augen von Brzezinski nach einer terroristischen Lösung, sodass der radikale Terror nolens volens die natürliche Reaktion der Führungselite des Regimes darstellte, der allerdings mit zunehmender Stabilität der totalitären Herrschaft nur noch als permanente Säuberung zu verstehen sei. In Löwenthals Beitrag Der Hintergrund der Säuberungen tauchte die Verknüpfung von Revolution und Säuberung als ein zentraler Aspekt bei seiner Interpretation des Phänomens der Parteisäuberung wieder auf.

Bei Löwenthal selber mündeten die angesprochenen historisch-analytischen Erkenntnisse aus seinem Beitrag Der Hintergrund der Säuberungen in seinen im Jahre 1960 veröffentlichten Aufsatz Totalitäre und demokratische Revolution ${ }^{481}$. Für Löwenthal waren die entscheidenden Merkmale eines totalitären Herrschaftsregimes einerseits in der Machtstruktur und zum anderen in der Dynamik der Systeme zu sehen. Seiner Meinung nach war das durch eine revolutionäre Partei konstituierte Herrschaftssystem insgesamt als totalitär zu klassifizieren, weil das durch eine »totalitäre Revolution « an die Macht gekommene Einparteienregime permanent versucht, »die Gesellschaft weiter im Sinne ihrer Ideologie zu transformieren«. Löwenthal zufolge war das historisch Besondere und »geschichtlich Beispiellose « an den totalitären Regimen, wie er schrieb, dass sie "Macht nicht nur mit revolutionären Methoden erobern, sondern sie durch zielbewußtes Inganghalten eines Prozesses gelenkter gesellschaftlicher Umwälzung zu behaupten suchen - daß sie eine >permanente Revolution von oben anstreben. $^{482}$

Angesichts der in dem Beitrag Der Hintergrund der Säuberungen aufgeworfenen Fragen und des Versuches, die stalinistischen Säuberungen in der Sowjetunion, den Satellitenstaaten sowie in der Kommunistischen Partei Frankreichs nach dem Ende des Zweiten Weltkriegs zu erklären, stand also für Löwenthal grundsätzlich fest, dass es sich beim sowjetkommunistischen Herrschaftssystem - eingedenk seiner theoreti-

481 Richard Löwenthal, Totalitäre und demokratische Revolution, in: Der Monat 13 (1960), H. 146, S. 2940; der Beitrag liegt indes außerhalb des in diesem Teil der vorliegenden Arbeit zugrunde liegenden Untersuchungszeitraumes.

482 Ebd., S. 31. 
schen Ausgangserkenntnis, dass es zum Wesen des sowjetischen Staates sowohl unter Lenin als auch unter Stalin gehörte, von einem »Gesetz der permanenten Revolution« vorangetrieben zu werden, und dass dies die eigentliche Triebkraft des Regimes war um ein totalitäres Einparteienregime handelte, bei dem es vor dem Hintergrund der kommunistischen Ideologie einen direkten Zusammenhang gab zwischen innenpolitischer und außenpolitischer Entwicklung. Das heißt, in seinen Augen fielen die innere und die äußere Politik der Sowjetunion letzten Endes zusammen. Aus diesem Grund war Löwenthal imstande, erstens einen Zusammenhang herzustellen zwischen der sich vor allem im Jahre 1948 zugespitzten politischen Situation des Kalten Krieges und den politischen Entwicklungen in der Sowjetunion sowie in den Satellitenstaaten, ${ }^{483}$ zweitens, dass die einzelnen stalinistischen Terroraktionen nicht als jeweils einzelnes Phänomen aufzufassen waren, sondern das ein »inneres Band « ${ }^{484}$ zwischen den Säuberungen in den internationalen kommunistischen Parteien und den (öffentlichen und nicht öffentlichen) Schauprozessen und mithin zwischen der »ersten Welle« (1948/49) und "zweiten Welle« (1952/53) existierte, drittens, dass der stalinistische Terror und die Parteisäuberungen nicht in erster Linie einem »scheinbaren Wahnsinn« Stalins oder der »Führungsclique« des sowjetischen Einparteienregimes geschuldet waren.

Konkret gesprochen hieß das mit Blick auf die »erste Welle« der stalinistischen Säuberungen in den Jahren 1948/49, dass, nachdem der außenpolitische Expansionismus des sowjetischen Kommunismus unter der Führung Stalins in Richtung Westeuropa infolge des »ernsten westlichen Widerstand[es]« in die Defensive gezwungen wurde - exemplarischer, symbolträchtiger Ausdruck war die Berliner Luftbrücke 1948 -, also der sowjetische außenpolitische Expansionsdrang eingedämmt war und Moskau zudem, infolge des Ausbruches Jugoslawiens unter Tito aus dem sowjetischen Machtbereich, in den Augen der sowjetischen Führungsmannschaft im Politbüro in eine existenzielle Krise geraten war, sich für Löwenthal aus systemimmanenten Gründen sich ebendiese Krise einerseits auf die sowjetische Innenpolitik und andererseits auf die sowjetische Strategie in den Satellitenstaaten auswirken musste. Da die sowjetische außenpolitische Nachkriegsstrategie, also die Strategie »hemmungsloser Expansion «, in eine ernsthafte Krise geraten war, hatte dies zwangsläufig einen veränderten, defensiveren Kurs »nach außen« zur Folge, und so musste aus systemimmanenten Gründen - so können die Ausführungen von Löwenthal gelesen werden »nach innen" vor allem aus zwei Gründen die stalinistischen Säuberungen 1948/49 in Gang gebracht werden:

Erstens wurden die Vertreter der sogenannten fortgesetzten hemmungslosen Expansion ausgeschaltet und in den allermeisten Fällen liquidiert - vor allem im Politbüro der KPdSU und in den Politbüros der kommunistischen Parteien der Satellitenstaaten;

Zweitens wurden aus systemimmanenten Gründen die Führer der kommunistischen Parteien in den Satellitenstaaten liquidiert, um "potentielle Titos « zu verhindern und mithin eine zusätzliche Schwächung des sowjetischen Herrschaftssystems

483 Vgl. zu den näheren politischen Hintergründen und Einzelheiten: Franz Borkenau, Der europäische Kommunismus. Seine Geschichte von 1917 bis zur Gegenwart, Bern 1952, S. 488-514.

484 Vgl. hierzu auch ders., Doppelsäuberung in der Tschechoslowakei, in: Ost-Probleme 3 (1951), Nr. 49, S. 1511-1514. 
$\mathrm{zu}$ verhindern. Nachdem infolge des »Abfalls Titos« das »Experiment«, den osteuropäischen »Volksdemokratien« unter der Führung der Kominform eine gewisse Unabhängigkeit zu gewähren bzw. ihnen eine gewisse Eigeninitiative für einen »nationalen Weg« des Kommunismus zu lassen, für die sowjetische Führung gescheitert war zumal mit der »Balkanförderation« die konkrete Gefahr eines mit Moskau konkurrierenden Machtzentrums bestand -, war die Kremlführung zum Handeln gezwungen.

Vor diesem Hintergrund gab es zum Zeitpunkt der Veröffentlichung von Löwenthals Beitrag Anfang des Jahres 1953 überzeugende Anhaltspunkte für seine originelle und grundsätzliche Interpretation der »ersten Welle« der stalinistischen Säuberungen 1948/49 in der Sowjetunion nach dem Tod von Schdanow. In der Tat war der Tod des Schdanow im Sommer 1948 das Startzeichen für die Parteisäuberung, die in der Kommunismusforschung der 1950er-Jahre als »Leningrader Affäre« (Boris Lewytzkyj) einging. Von Löwenthal wurde zu Recht darauf insistiert, dass Schdanow und Wosnessenski (einer der führenden Leningrader Parteifunktionäre) im Politbüro sowie in der Partei einerseits zu den vehementen Befürwortern einer radikalen außenpolitischen Expansion der Sowjetunion zählten - insbesondere was den offensiven militärischen Kurs gegenüber den westlichen kapitalistischen Staaten anbelangte - und andererseits vor dem Hintergrund der schdanowschen Kominform-Politik Jugoslawiens Unabhängigkeitskurs von Moskau erst möglich machte; Wosnessenski hatte zudem nach dem Tod von Schdanow den Ruf, eine oppositionelle Position im Hinblick des Anti-Tito-Kurses der sowjetischen Führung vertreten zu haben. Das heißt, dass Löwenthal zum damaligen Zeitpunkt eine zweifelsohne überzeugende, stichhaltige Interpretation lieferte, warum führende Funktionäre nach dem Tod von Schdanow aus der Partei ausgeschlossen und zum Teil liquidiert wurden: Demnach handelte es sich um Parteifunktionäre, die von Schdanow persönlich ernannt wurden und mithin wie zum Beispiel Wosnessenski im Verdacht standen, Befürworter von dessen politischen Kurs zu sein.

Ebenso war die Interpretation der Säuberungen und der Schauprozesse in den Satellitenstaaten von Löwenthal überzeugend, wonach mit der Verhaftung und Liquidierung führender Funktionäre der nationalen kommunistischen Parteien seitens der Kremlführung in erster Linie das Ziel verfolgt wurde, zu verhindern, dass die Führung der einzelnen Staaten Tito als Vorbild nehmen und einen von Moskau unabhängigen politischen Kurs einschlagen könnten. Das heißt, dass es der sowjetischen Führung primär auf die Sicherung des kommunistischen Herrschaftssystems im Allgemeinen und die Konsolidierung der Macht in den osteuropäischen »Volksdemokratien« im Besonderen ging. Anders gesagt, es ging bei den Säuberungen in den Satellitenstaaten insbesondere um die Sicherung des tatsächlich imperialistischen Systems Moskaus. ${ }^{485}$ Insofern lag Löwenthal mit seiner impliziten Interpretation der sowjetischen Schauprozesse in Bulgarien und Ungarn im Jahre 1949 richtig, dass unter anderem das Mitglied des ungarischen Politbüros Rajk und das Mitglied des bulgarischen Politbüros Kostow deshalb auf der Anklagebank saßen, verurteilt und erhängt wurden, um »potentielle Titos« zu verhindern. ${ }^{486}$ Aus diesem Grund war es auch nicht entscheidend, ob die Angeklagten, die als »Verräter« betrachtet wurden, tatsächlich

485 Zum sowjetischen Imperialismus vgl. grundsätzlich David ]. Dallin, Rußlands neuer Imperialismus,

in: Ost-Probleme 2 (1950), Nr. 48, S. 1499-1507.

486 James Burnham, Die Strategie des Kalten Krieges, Stuttgart 1950, S. 153. 
einen von Moskau unabhängigen politischen Weg gehen wollten, d. h. also einen "nationalen Kommunismus « favorisierten. Analog zu den Moskauer Schauprozessen in den 1930er-Jahren ging es hierbei nicht darum, ob die Angeklagten tatsächlich Schuld oder Unschuld hatten. Sie saßen nicht zufällig als führende Parteifunktionäre auf der Anklagebank, sondern wurden stellvertretend als »titoistische Verräter« verurteilt. Jedem Mitglied der kommunistischen Partei in Ungarn und Bulgarien (sowie in den anderen osteuropäischen Ländern) sollte unmissverständlich signalisiert werden, dass letzten Endes jeder in den Verdacht geraten konnte, ein »Verräter « und "potentieller Tito« zu sein. Aus diesem Grund spielte Tito in den Schauprozessen auch eine Schlüsselrolle. Auch wenn Löwenthal diesen Sachverhalt nicht explizit zum Ausdruck brachte: Bei den Schauprozessen in Ungarn und Bulgarien war der Kernpunkt der Anklage, dass die Parteifunktionäre geheime Verbindungen zu Tito hatten. Bemerkenswerterweise wies Löwenthal bereits darauf hin, dass der »irgendwo hinter dem eisernen Vorhang "verhaftete amerikanische Kommunist Noel Field eine Schlüsselfigur sowohl in den Schauprozessen als auch in den Säuberungen des Kominform-Apparates und den kommunistischen Parteien bzw. »des kommunistischen Geheimapparates in ganz Europa « war. Field wurde kurze Zeit nach dem Bruch zwischen Tito und Stalin in Ungarn als angeblicher Verbindungsmann des amerikanischen Geheimdienstes verhaftet. Ohne dass Field in den Schauprozessen in Ungarn und in Bulgarien (als auch zum Beispiel im Slánský-Prozess) in irgendeiner Form in Erscheinung trat, nicht als Angeklagter oder als Zeuge, spielte er trotzdem eine zentrale Rolle. In den Augen der Moskauer Führung, so können die Ausführungen von Löwenthal gelesen werden, entwickelte sich im Kontext der »antititoistischen Kampagne« eine - man könnte sagen - paranoide Unterwanderungsfurcht, sodass alle die Personen, die im Verdacht standen, entweder mit Field direkt Kontakt oder sonst zu irgendeinem Zeitpunkt "geheime Verbindungen zum Westen« gehabt zu haben - und mithin vom »westlichen Virus « infiziert waren -, als potenzielle Gefahr für die Sowjetunion angesehen wurden und dementsprechend Opfer von unterschiedlichen Verfolgungsmaßnahmen wurden. ${ }^{487}$

Auch die Interpretation der "zweiten Welle« der sogenannten internationalen Säuberung in den Monaten unmittelbar vor dem Tod Stalins war nicht zuletzt angesichts der Tatsache, dass der Zeitzeuge und Kommunismusexperte Löwenthal selbstverständlich keinen Zugang zu den sowjetischen Archiven hatte und sich möglicherweise ausschließlich auf die in der Zeitschrift Ost-Probleme veröffentlichten offiziellen sowjetischen »Presseartikel (zum Beispiel Prawda oder Iswestija) als Quelle stützten konnte, zweifelsohne überzeugend. Überhaupt den Versuch zu unternehmen, zu erklären, warum der - bis auf »kleine Ausnahmen« in der Tschechoslowakei zu Beginn der 1950er-Jahre - stalinistische Terror, genauer gesagt, die "ganzen internationalen Säuberungen« Ende der 1940er-Jahre zum Stoppen kam, um dann nach einer Inkubationszeit von knapp vier Jahren Ende 1952 bzw. Anfang 1953 wieder in Gang gesetzt zu werden, machte den Beitrag Der Hintergrund der Säuberungen zu einer genuinen Untersuchung zur Bedeutung des Terrors im sowjetkommunistischen Herrschaftssystem unter Stalin.

Allerdings blieben im Hinblick auf die Interpretation für das Wieder-in-GangKommen der innerparteilichen Säuberungen bei Löwenthal in diesem Zusammen- 
hang »offene Fragen«. Letzten Endes erklärte er die »zweite Welle« der Parteisäuberung damit:

1. Dass zu Beginn der 1950er-Jahre, vor allem nach dem »Südkorea-Desaster« im Sommer 1950, in der sowjetischen Führung, also im Politbüro, keine Klarheit über die zukünftige sowjetische Außenpolitik bzw. über die »neue Politik gegenüber dem Westen« herrschte und dass die Funktionäre Opfer der Säuberungen wurden, die einer expansiven sowjetischen Außenpolitik das Wort redeten. Das heißt, Löwenthal zufolge wurden in den kommunistischen Satellitenstaaten mit Slánský und Pauker - die von ihm exemplarisch genannt wurden - nämlich »Vertreter einer aggressiven Außenpolitik« Opfer der zweiten Säuberungswelle und stellte in diesem Zusammenhang eine politische Verbindung zu der zurückliegenden Ausschaltung von Wosnessenski aus dem Jahre 1949 her, der bis dahin als Hauptbefürworter einer offensiven sowjetischen Außenpolitik im Politbüro galt; zumal er, so Löwenthal, »Shdanows wichtigster Verbündeter im Politbüro« war, der wiederum als Vertreter der These vom »überlegenen Kriegspotenzial der kommunistischen Welt« galt.

2. Dass vor dem Hintergrund seiner theoretischen Prämisse, dass es sich bei der Sowjetunion um ein totalitäres Regime handelte, dessen originäre Triebkraft das »Gesetz der permanenten Revolution von oben«war, sich die Kremlführung dafür entschieden hatte, die gefahrvolle außenpolitische Expansionspolitik zwischenzeitlich aufzugeben, um die »Hauptenergien« des Regimes, so Löwenthal, »einstweilen den nächsten Stufen der inneren Revolution « vor allem in den osteuropäischen Satellitenstaaten zu widmen; für den anvisierten Gleichschaltungsprozess (verstärkte Kollektivierung der Landwirtschaft und forcierter Aufbau der Schwerindustrie nach sowjetischen Vorbild) gab es aus Löwenthals Sicht überzeugende Anhaltspunkte. Insoweit waren die Argumentationslogik im Hinblick auf die Interpretation der wieder angelaufenen »Säuberungswelle« in den osteuropäischen Satellitenstaaten in sich stimmig, plausibel und freilich aufgrund der »Archivsituation « und der zeitlichen Koinzidenz mit dem politischen Phänomen der stalinistischen Säuberungen sowie der »Ärzteaffäre« in der Sowjetunion selbstverständlich in hohem Maße spekulativ - wie es Löwenthal in seinem Beitrag auch ausdrücklich konzedierte.

Allerdings litt der gesamte Beitrag Der Hintergrund der Säuberung an dem zentralen Problem, dass sich Löwenthal letzten Endes über die Rolle Stalins nicht eindeutig im Klaren war bzw. sie nicht klar zur Sprache brachte. Im Hinblick auf die politischen Säuberungen in der Sowjetunion und speziell zu der von ihm angesprochenen »Ärzteaffäre« unmittelbar vor dem Tod Stalins bedeutete dies, dass Löwenthal nicht den "Schlüssel« besaß, um die Vorgänge mit größerer analytischer Sicherheit zu interpretieren. Einerseits ging der Autor explizit und implizit von einer »kollektiven Führung« in der Sowjetunion und folglich von der überragenden Herrschaftsfunktion des Politbüros aus sowie in diesem Kontext wiederum von einem internen Richtungsstreit in der »Kremlführung« und einem Machtkampf unter den staatlichen Apparaten (exemplarisch: Schdanow/Wosnessenski-Fraktion versus Malenkow-Fraktion). Andererseits hielt es Löwenthal in Bezug auf die "Ärzteaffäre« ausdrücklich für möglich, dass es sich ausschließlich um ein »zynisches Meisterstück Stalins« handelte. ${ }^{488}$

488 Zu den letzten Säuberungen im Stalinismus mit Blick auf die genaue Rolle Stalins vgl. bes. Leonhard, Kreml ohne Stalin, S. 67-79. 
Das will heißen: Löwenthal hatte letzten Endes zum damaligen Zeitpunkt keine klare Vorstellung über die Rolle von einzelnen Akteuren, konkret von Stalin im Kontext seiner Theorie des totalitären sowjetkommunistischen Herrschaftssystem. In seiner theoretischen Grundkonzeption, demzufolge die eigentliche Triebkraft des bolschewistischen Einparteienregimes das »Gesetz der permanenten Revolution«bzw. Stalins "permanente Revolution von oben« war, lag der analytische Fokus zu stark auf der Machtstruktur, auf dem Systemcharakter und, vor dem Hintergrund der Verknüpfung von »Revolution und Ideologie«, zu stark auf dem Sowjetkommunismus als "totalitäre Bewegung«, sodass dementsprechend der Schwerpunkt in starkem Maße auf der »Partei«, auf den »Apparaten« und in letzter Konsequenz auf der sowjetischen Führung im »Politbüro« lag; wobei selbstverständlich die Rolle von einzelnen führenden Parteifunktionären, wie gezeigt wurde, keineswegs in Gänze heruntergespielt oder gar geleugnet wurde und was auch dadurch zum Ausdruck kam, dass es für Löwenthal fest stand, dass es einen politisch-ideologischen Machtkampf in der »Führungsclique« gab. Hinzu konstatierte er auch, dass Stalins »letzte Abhandlung« in dem von Löwenthal thematisierten Komplex die »theoretische Leitschrift« darstellte.

Damit soll zum Ausdruck gebracht werden, dass vor dem Hintergrund der Interpretation der ersten und zweiten »Welle« der (internationalen) Säuberungen Löwenthals, im Hinblick auf seine anvisierte Analyse des sowjetischen Herrschaftssystem im Allgemeinen und der kommunistischen Führungselite in der Sowjetunion im Besonderen auffallend war, dass der Kommunismusexperte letztlich eine nichtstalinzentrierte, polykratische Perspektive einnahm. Einerseits betrachtete er zu Recht das Politbüro als zentrale Herrschaftsinstitution des sowjetischen Staates. Andererseits ging er davon aus, dass sich in den Jahren nach dem Zweiten Weltkrieg im Politbüro der KPdSU zwei konkurrierende Gruppen mit unterschiedlichen politischen Zielvorstellungen gegenüberstanden und im Grunde genommen Stalin ein »normales« Mitglied ebendieser sowjetischen Machthaber war. Genauer gesagt, bei der Analyse des kommunistischen Herrschaftsapparates von Löwenthal kam letzten Endes nicht eindeutig zum Ausdruck, welche Rolle Stalin in diesem Kontext spielte. Dementsprechend wurde von Löwenthal auch nicht beleuchtet, ob nicht Stalin der Hauptverantwortliche für die Parteisäuberung war und ob nicht ein Motiv beispielsweise für die Säuberungen der KPdSU oder des Politbüros darin zu sehen war, dass Stalin möglicherweise »Sündenböcke« bzw. »Schuldige« für eine falsche, für eine von ihm zu vertretene fehlgeschlagene Innen- und Außenpolitik brauchte. So wurde von ihm nicht thematisiert, ob nicht zum Beispiel Wosnessenski - der seit 1947 Mitglied im Politbüro des ZK der KPdSU war und als Fachmann für Wirtschaftsfragen galt - als ein Hauptverantwortlicher für die wirtschaftlichen Schwierigkeiten in der Sowjetunion infolge einer Fehlplanung im Kontext des Zweiten Fünfjahresplanes nach dem Zweiten Weltkrieges ausgeschaltet und liquidiert wurde. ${ }^{489}$

Insgesamt war an den Ausführungen von Löwenthal zudem auffallend, dass sein Blick ausschließlich auf die Elite der kommunistischen Partei in der Sowjetunion und den osteuropäischen Satellitenstaaten fiel. Zum einen war dies verständlich, weil es um die historische Interpretation der »internationalen « Parteisäuberung ging; wobei hier auch wiederum der Fokus auf die unmittelbare Parteielite gerichtet wurde, so-

489 Vgl. hierzu Georg von Rauch, Geschichte des bolschewistischen Rußland, Wiesbaden 1955; hier nach der Taschenbuchausgabe, Frankfurt a. M./Hamburg 1963, S. $419 f$. 
dass nicht thematisiert wurde - möglicherweise fehlten zum damaligen Zeitpunkt noch gesicherte detaillierte Informationen -, dass auch die unteren Ränge der Partei, also auch die »einfachen« Parteimitglieder, gesäubert wurden. ${ }^{490}$ Zum anderen wurde von Löwenthal nicht ausdrücklich angesprochen, dass vom stalinistischen Terror nach dem Ende des Zweiten Weltkrieges Millionen sowjetischer Bürger aufgrund von Massen- und Bevölkerungsdeportationen betroffen waren und unter anderem Zwangsarbeit in den sowjetischen Lagern leisten mussten. Bei Löwenthal war ausschließlich davon die Rede, dass dem »russischen Volk« im Kontext der allgemeinen staatlichen Industriepolitik »schwere Opfer « auferlegt wurden. ${ }^{491}$

\subsection{Der Nachstalinismus: das kommunistische Herrschaftssystem unter Chruschtschow}

Nach dem für die Weltöffentlichkeit überraschenden Tod von Stalin am 5. März 1953 setzte in der Zeitschrift Der Monat sofort eine Diskussion ein, die sowohl politische als auch theoretische Aspekte beinhaltete und die vor allem im Kern die analytisch ausgerichtete Frage fokussierte, welche Bedeutung das Ableben des unumstrittenen Parteiführers für das sowjetkommunistische Herrschaftssystem haben könnte. Das hieß in diesem Zusammenhang auch, dass seitens verschiedener Autoren die Frage thematisiert wurde, welche innen- und außenpolitische Entwicklung die Sowjetunion nehmen könnte. Es ging also hierbei auch um die sich besonders angesichts des Kalten Krieges aufdrängende Frage, welche grundsätzliche politische und gesellschaftliche Entwicklung das nachstalinistische System nehmen könnte, ob die Sowjetunion möglicherweise expansive außenpolitische Ziele verfolgen und insofern in den Augen der westlich-demokratischen Staaten eine unmittelbare militärische Bedrohung darstellen würde. Angesichts der zeitlichen Aktualität besaßen die Veröffentlichungen selbstverständlich einen hochspekulativen Charakter, ging es doch darum, ebendiese mögliche Veränderung der Sowjetunion nach Stalins Tod zu prognostizieren, also vorherzusagen. Denn es ging nicht zuletzt auch um die Frage, ob sich der »Stalinismus nach Stalin« wandeln könnte. Zudem enthielten einige Veröffentlichungen auch detaillierte Informationen zur zurückliegenden Geschichte der Sowjetunion - wie zum Beispiel zur Rolle des Geheimdienstes und einzelnen Funktionären.

Diese umfangreiche Diskussion implizierte freilich im Laufe der Zeit auch die Frage, inwiefern nach dem Tod Stalins streng genommen noch im Hinblick auf die Analyse des sowjetkommunistischen Regimes von einem totalitären Herrschaftscharakter ausgegangen werden kann und ob in diesem Zusammenhang der Begriff des Stalinismus noch anzuwenden sei. Zudem wurde die grundsätzliche Frage beleuchtet - die

490 Siehe Leonhard, Kreml ohne Stalin, S. 271.

491 Vgl. neben den bereits genannten Veröffentlichungen aus der (Forschungs-)Literatur zum Thema »Zwangsarbeit« und sowjetische Konzentrationslager exemplarisch: Toni Sender, Zwangsarbeit, in: Ost-Probleme 2 (1950), Nr. 12, S. 385-388; Materialien zur Frage der Zwangsarbeit, in: Ost-Probleme 2 (1950), Nr. 35, S. 1107-1110 (Erstveröffentlichung: Journal de Ceneve, Cenf, 18. August 1950); Elinor Lipper, Elf Jahre in Sowjetgefängnissen und Lagern, Zürich 1950; Marta Rudzka, Workuta. Weg zur Knechtschaft, Zürich 1948; H. S., Bericht über sowjetische Lager - bearbeitet auf Crund der offiziellen Protokolle der Internationalen Kommission zum Kampf gegen das Regime der Konzentrationslager, in: Ost-Probleme 3 (1951), S. 1162-1183. 